\title{
TELESEISMIC SOURCE PARAMETERS AND RUPTURE CHARACTERISTICS OF THE 24 NOVEMBER 1987, SUPERSTITION HILLS EARTHQUAKE
}

\author{
By Lorraine J. Hwang, Harold Magistrale, and Hiroo Kanamori
}

\begin{abstract}
Long-period body waves from the 24 November 1987, Superstition Hills earthquake are studied to determine the focal mechanism and spatial extent of the seismic source. The earthquake is a complex event consisting of two spatially distinct subevents with different focal mechanisms. Two consistent models of rupture are developed. For both models, the second subevent begins $8 \mathrm{sec}$ after the initiation of the first subevent and the preferred centroid depth lies between 4 to $8 \mathrm{~km}$. Model 1 consists of two point sources separated by 15 to $20 \mathrm{~km}$ along strike of the Superstition Hills fault. Model 2 consists of one point source and one line source with a rupture velocity of $2.5 \mathrm{~km} / \mathrm{sec}$ with moment release distributed along strike of the focal plane at a distance of 10 to $22 \mathrm{~km}$ from the epicenter. These moment release patterns show that a significant amount of long-period energy is radiated from the southern segment of the fault. Total moment release for both models is approximately $8 \times 10^{25}$ dyne-cm. Both models also suggest a change of dip from near vertical near the epicenter to steeply southwesterly dipping along the southern segment of the fault. The difference in rupture characteristics and fault dips seen teleseismically is also reflected in aftershock and afterslip data, and crustal structure underlying the two fault segments. The northern segment had more aftershocks and a smaller proportion of afterslip than the southern segment. The boundary between the two segments lies at a step in the basement that separates a deeper metasedimentary basement to the south from a shallower crystalline basement to the north.
\end{abstract}

\section{INTRODUCTION}

The 24 November 1987, Superstition Hills earthquake sequence occurred in the western Imperial valley in southern California. The earthquakes took place on a conjugate fault system consisting of the right-lateral, northwest-striking Superstition Hills fault and the left-lateral, northeast-striking Elmore Ranch fault (Fig. 1). The earthquake sequence consisted of foreshocks, an $M_{s} 6.2$ main shock, and aftershocks on the Elmore Ranch fault followed by an $M_{s} 6.6$ main shock and aftershocks on the Superstition Hills fault (Magistrale et al., 1989). The epicenter of the Superstition Hills main shock is located near the intersection of the two faults. The Superstition Hills fault ruptured the surface in three strands (Sharp et al., 1989): the north and south segments of the Superstition Hills fault, and the Wienert fault to the south (Fig. 1). The fault strands are separated by narrow right steps. Previous geologic and seismologic investigations (Hanks and Allen, 1989) provide useful constraints for this teleseismic study. The strike of the surface rupture (Sharp et al., 1989) constrains the plane of fault rupture and the distribution of aftershocks (Magistrale et al., 1989) indicates a depth range of moment release to investigate.

The Superstition Hills earthquake was recorded by nearby strong motion instruments, and local and teleseismic seismic networks. Source studies of this earthquake by several authors utilize these data and provide a general picture of this earthquake over a broad frequency range. Frankel and Wennerberg (1989) inverted high 


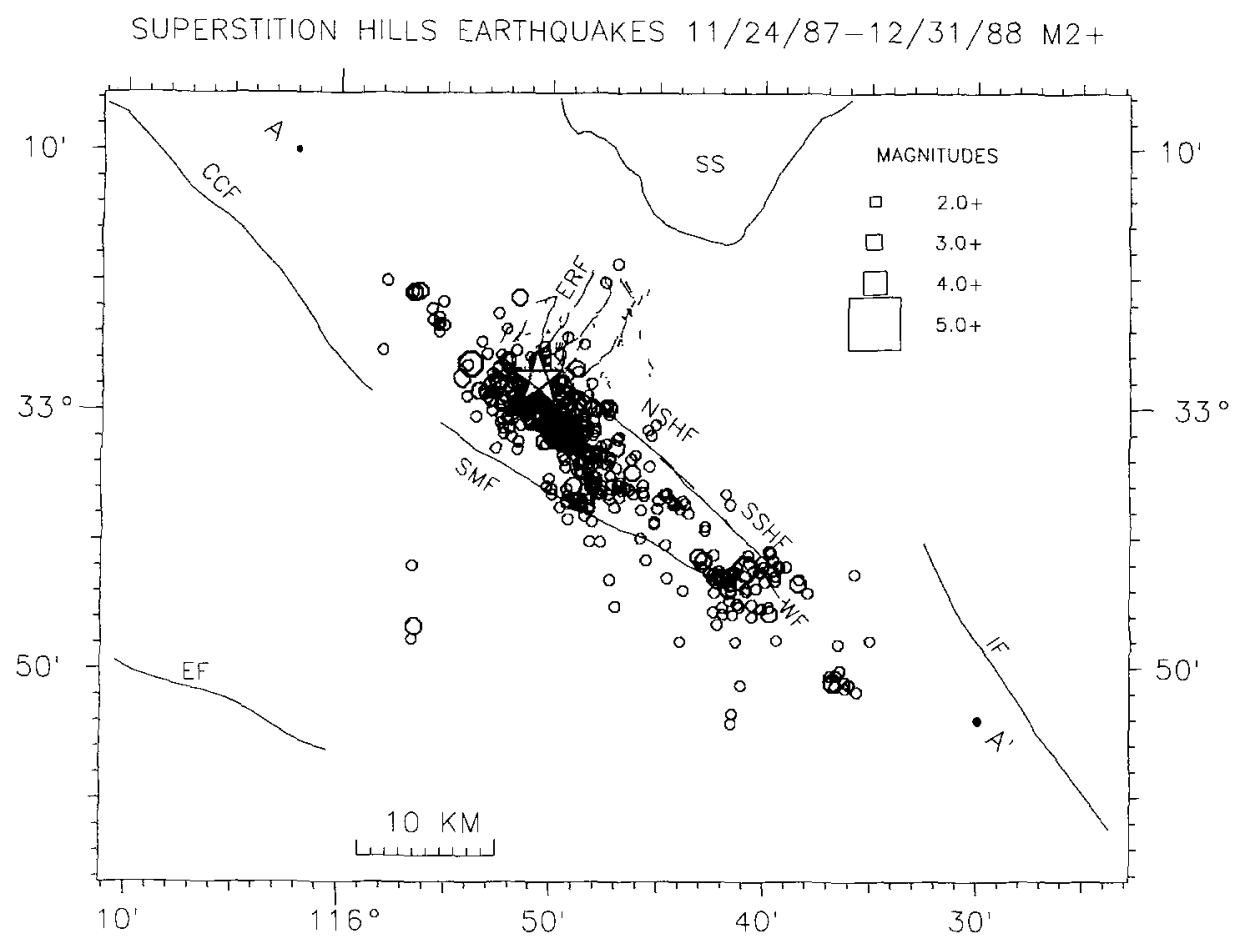

FIG. 1. The 24 November 1987 Superstition Hills earthquake (star) and $M_{L} \geqq 2$ aftershocks from $11 / 24 / 87$ to $12 / 31 / 88$. Symbol size is scaled to earthquake magnitude. AA' is the location of the cross section shown in Figure 2. Earthquake location technique is described in Magistrale et al. (1989). The trace of the Elmore Ranch and Superstition Hills fault rupture is from Sharp et al. (1989). Abbreviations: NSHF, northern segment of the Superstition Hills fault; SSHF, southern segment of the Superstition Hills fault; WF, Wienert fault; ERF, Elmore Ranch Fault; SMF, Superstition Mountain fault; CCF, Coyote Creek fault; EF, Elsinore fault; IF, Imperial fault; and SS, Salton Sea.

frequency strong-motion recordings using a tomographic source inversion technique to determine timing, location, one-dimensional extent and rupture velocity of three subevents. The effective rupture velocity between the two principal subevents, subevents 2 and 3 , is very slow but their individual velocities are greater than or equal to the shear-wave velocity of the medium, respectively. Depth was determined from waveform complexity.

Bent et al. (1989) forward modeled long-period regional and teleseismic $P$ and SH waveforms using a method based on ray summation (Langston and Helmberger, 1975). They determined focal mechanism, depth, timing, and source separation distance for two subevents that have different mechanisms. For their second subevent, they investigated both point and distributed source models. The solutions for the different models were not significantly different. Their preferred model explains the event as two distinct point sources separated in time and space.

Sipkin (1989) inverted teleseismic long-period waveforms using a time-dependent moment-tensor algorithm to resolve a time varying moment tensor and a detailed source time function. He modeled this earthquake with a complex source time function consisting of two subevents with no significant change in focal mechanism. In his model, sources were constrained to occur at the same location and focal depth. Source parameters from these studies are summarized in Table 1.

Several important questions are not well resolved by the above studies. No model clearly determines whether any moment release occurred on the Elmore Ranch 
TABLE 1

MODEL PARAMETERS

\begin{tabular}{|c|c|c|c|c|c|c|c|c|c|}
\hline Model & $\begin{array}{l}\text { Strike } \\
\text { (deg) }\end{array}$ & $\begin{array}{l}\text { Dip } \\
\text { (deg) }\end{array}$ & $\begin{array}{c}\text { Slip } \\
\text { (deg) }\end{array}$ & $\begin{array}{c}\text { Depth } \\
(\mathrm{km})\end{array}$ & $\begin{array}{c}\text { Delay } \\
(\mathrm{sec})\end{array}$ & $\begin{array}{l}\text { Velocity } \\
(\mathbf{k m o} / \mathrm{sec})\end{array}$ & $\begin{array}{c}\text { Distance } \\
(\mathrm{km})\end{array}$ & $\begin{array}{l}\text { Azimuth } \\
\text { (deg) }\end{array}$ & $\begin{array}{c}\text { Moment } \\
(\text { dyne-cm }) \times 10^{25}\end{array}$ \\
\hline MJK & 305 & 90 & 180 & 2 & & & & & \\
\hline \multirow[t]{3}{*}{$\mathrm{FW}^{\dagger}$} & 128 & 90 & 180 & 9 & 0 & & & & \\
\hline & 128 & 90 & 180 & 9 & 3 & 5.3 & 2 & & $0.37^{*}$ \\
\hline & 128 & 90 & 180 & 9 & 9.7 & 3 & 8 & & $1.4^{*}$ \\
\hline $\mathrm{S}$ & 303 & 89 & -180 & 10 & $5-9$ & & 0 & 0 & 10 \\
\hline HRV & 133 & 78 & 178 & 15 & & & & & 7.2 \\
\hline \multirow[t]{2}{*}{ BHSH } & 305 & 80 & 175 & 10 & 0 & & 0 & 0 & 3.6 \\
\hline & 320 & 80 & 175 & 6 & 7.5 & & 30 & 180 & 7.2 \\
\hline \multirow[t]{2}{*}{ HMK1 } & 120 & 88 & 194 & 4 & 0 & & 0 & 0 & 2.4 \\
\hline & 126 & 69 & 182 & 6 & 8.1 & & 20 & 125 & 5.2 \\
\hline \multirow[t]{2}{*}{ HMK2 } & 122 & 82 & 194 & 4 & 0 & & 0 & 0 & 3.1 \\
\hline & 125 & 63 & 178 & 6 & 8.2 & 2.5 & 22.5 & 125 & 4.8 \\
\hline
\end{tabular}

* Moment at $\sim 1 \mathrm{~Hz}$.

$\uparrow$ Assumed focal mechanism.

Abbreviations: MJK: Magistrale et al. (1989); FW: Frankel and Wennerberg (1989); S: Sipkin (1989); HRV: Harvard Centroid Moment Tensor; BHSH: Bent et al. (1989); HMK1: Hwang et al. (this study), model 1; HMK2: Hwang et al. (this study), model 2.

fault during the Superstition Hills earthquake and if all the segments of the Superstition Hills fault ruptured coseismically. Frankel and Wennerberg (1989) investigated rupture to the northeast of the epicenter along the Elmore Ranch fault. This rupture direction improved the waveform and amplitude fits to strong-motion records to the northeast, but records at other azimuths had worse or similar fits to their preferred model of rupture along the Superstition Hills fault. Wald and Somerville (1988) also propose that a subevent ruptured the Elmore Ranch fault. However, Frankel and Wennerberg (1989) point out that the lack of aftershocks along the Elmore Ranch fault following the Superstition Hills earthquake does not support rupture of the Elmore Ranch fault during the Superstition Hills earthquake. Sipkin (1989) does not consider spatial separation of subevents. Bent et al. (1989) placed their second subevent due south of the first subevent. The distance between subevents is poorly resolved. If their first subevent is near the north end of the Superstition Hills fault, their preferred model would place the second subevent substantially off the surface trace of the Superstition Hills fault. Alternatively, restricting the first subevent to lie on the Elmore Ranch fault and the second subevent to lie on the Superstition Hills fault would place the first subevent at least $16 \mathrm{~km}$ northeast of the epicenter. By using an inverse method that allows for multiple source parameterizations, we improve on the resolution of directivity, rupture velocity, and spatial extent of the sources.

\section{Method and Data Preparation}

Teleseismic body waves were simultaneously inverted in a least-squares sense using the method of Nabelek $(1984,1985)$. This method can invert for multiple sources and solves simultaneously for focal mechanism, centroid depth, and source time function for each source and solves for the separation time, distance, and azimuth between the sources. Point and line sources were investigated. Since shortperiod data were not well recorded for this event, only long-period data are studied. The data set consists of long-period Global Digital Seismic Network (GDSN), Worldwide Standard Seismograph Network (WWSSN), and Canadian Network 
(CAND) $P$ and $S H$ waveforms (see Table 2) restricted to the distance range $30^{\circ} \leqq$ $\Delta \leqq 90^{\circ}$ for $P$ waves and $30^{\circ} \leqq \Delta \leqq 80^{\circ}$ for $S H$ waves to avoid regional and core effects. WWSSN and CAND data were digitized using an optical scanner, resampled at an interval of $0.25 \mathrm{sec}$ and corrected for drift.

Absolute timing of the $P$-wave arrival to each station is very important to resolve spatial extent and relationship between sources. Since this event was not well recorded on short-period instruments, the 1968 Borrego Mountain earthquake $(M$ $=6.8$ ) is used as a master event to compute travel-time delays. The 1987 Superstition Hills earthquake occurred close to the epicenter of the 1968 Borrego Mountain earthquake in a similar geologic setting. The Borrego Mountain earthquake was an impulsive event and well recorded worldwide. $P$-wave delay times are determined by subtracting the theoretical $P$-wave arrival times calculated from a Herrin earth model (Herrin, 1968) from the Borrego Mountain earthquake arrival times reported in the International Seismic Centre Bulletin. Since current station sites were not all occupied in 1968, arrival times to stations at similar azimuth and distance were used as noted in Table 2. Only one $S$-wave delay was available. $P$ - and $S$-wave delays are given in Table 2. These delays are added to the theoretical travel times for the Superstition Hills earthquake. In the inversion, the calculated and observed seismograms are not allowed to shift in time with respect to one another. However, seismograms from stations for which there is no $S$-wave delay are allowed to shift $\pm 10 \mathrm{sec}$. In the final solution, the seismograms shifted no more than \pm 5 sec relative to one another. For station SCP, the $P$-wave arrival for events during the month of November 1987 are systematically much later than the \pm 1 sec clock error reported during this time period. After studying waveforms from these other events, $10 \mathrm{sec}$ was added to the theoretical arrival time. It did not move from this time in the final solution.

The crustal velocity structure for the source region (Table 3) was taken after Fuis et al. (1982). This crustal velocity structure is intermediate between a velocity model of thick sediments overlying a metasedimentary basement characteristic of the central Imperial Valley east of the Superstition Hills fault and a velocity model representing thinner sediments over a granitic basement, as is typical to the northwest of the Superstition Hills fault (Fuis et al., 1982). The modeling results are only mildly sensitive to the source crustal model used.

TABLE 2

STATIONS

\begin{tabular}{|c|c|c|c|c|c|c|}
\hline Station & Instrument & $\begin{array}{c}\text { Azimuth } \\
\text { (deg) }\end{array}$ & $\begin{array}{c}\text { Distance } \\
\text { (deg) }\end{array}$ & Type & Weight & $\begin{array}{c}\text { Delay } \\
(\mathrm{sec})\end{array}$ \\
\hline GDH & DWWSSN & 24.4 & 49.8 & $P, S H$ & $0.70,0.60$ & $0,-$ \\
\hline $\mathrm{KONO}$ & ASRO & 25.1 & 77.3 & $P$ & 0.70 & 0 \\
\hline GRFO & SRO & 31.3 & 85.2 & $P$ & 0.70 & 1(STU) \\
\hline STJ & CAND & 53.2 & 49.0 &,$- S H$ &,- 0.35 & - \\
\hline $\mathrm{GAC}$ & SRO & 55.7 & 33.3 & $P, S H$ & $0.80,0.35$ & 1(OTT), - \\
\hline $\mathrm{SCP}$ & DWWSSN & 64.6 & 31.2 & $P, S H$ & $0.80,0.50$ & $*$ \\
\hline $\mathrm{BOG}$ & WWSSN & 116.8 & 48.1 & $P$ & 0.80 & 1 \\
\hline LPB & WWSSN & 129.6 & 67.1 &,$- S H$ &,- 0.35 & - \\
\hline ANT & WWSSN & 136.4 & 71.1 &,$- S H$ &,- 0.35 & 4 \\
\hline HON & DWWSSN & 263.5 & 39.0 &,$- S H$ &,- 0.60 & - \\
\hline MAJO & ASRO & 308.6 & 82.2 & $P$ & 1.00 & 2 \\
\hline $\mathrm{COL}$ & DWWSSN & 338.2 & 37.4 & $P, S H$ & $1.00,0.60$ & $0,-$ \\
\hline
\end{tabular}

* SCP had clock problems. See text. 
TABLE 3

\begin{tabular}{crccc}
\hline \multicolumn{5}{c}{ VELOCITY MODEL } \\
\hline $\begin{array}{c}\text { Thickness } \\
(\mathrm{km})\end{array}$ & $\begin{array}{c}\text { Depth } \\
(\mathrm{km})\end{array}$ & $\begin{array}{c}P \text {-Wave Velocity } \\
(\mathrm{km} / \mathrm{sec})\end{array}$ & $\begin{array}{c}S \text {-Wave Velocity } \\
\left(\mathrm{km} / \mathrm{sec}^{\mathrm{s}}\right)\end{array}$ & $\begin{array}{c}\text { Density } \\
\left(\mathrm{g} / \mathrm{cm}^{3}\right)\end{array}$ \\
\hline 1.5 & 0.0 & 2.5 & 1.4 & 2.3 \\
1.5 & 1.5 & 4.5 & 2.6 & 2.6 \\
9.5 & 3.0 & 6.2 & 3.6 & 2.6 \\
12.5 & 12.5 & 7.0 & 4.0 & 3.1 \\
& 25.0 & 7.9 & 4.6 & 3.3 \\
\hline
\end{tabular}

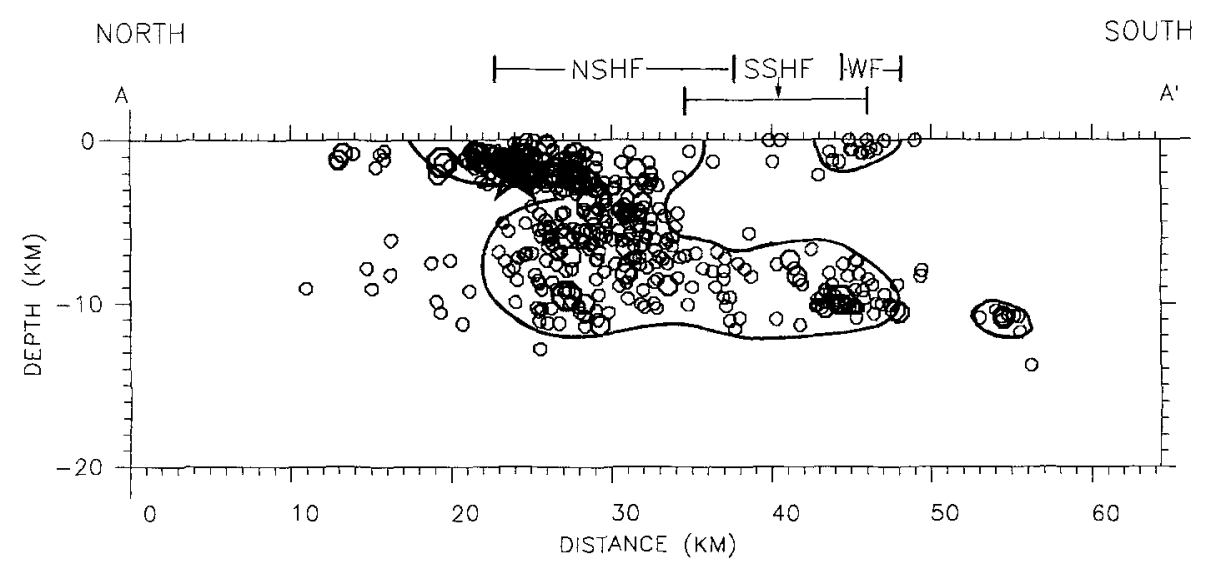

FIG. 2. Cross section parallel to the Superstition Hills fault. All events in Figure 1 within $10 \mathrm{~km}$ of cross section are projected onto the cross section. The aftershock zone is outlined. Earthquake symbols and abbreviations are the same as in Figure 1.

Data from the Southern California seismograph network define the source dimensions and location of this event (Magistrale et al., 1989). In the inversion, the locally determined focal mechanism (strike $305^{\circ}$, dip $90^{\circ}$, slip $180^{\circ}$ ) was used as the starting mechanisms. The nucleation point of the first subevent is constrained to the locally determined hypocentral depth of $2 \mathrm{~km}$ but the centroid depth may differ. Aftershock data defines the bottom of the seismogenic zone at a depth of $12 \mathrm{~km}$ and extends this zone to a distance of $30 \mathrm{~km}$ striking northwest-southeast along the Superstition Hills fault (Fig. 2). Multiple sources were constrained to lie along the fault plane with rupture velocities up to the shear-wave velocity of the medium, 3.5 $\mathrm{km} / \mathrm{sec}$. For subevent 1, sources along the Superstition Hills and Elmore Ranch fault were investigated. The above depth, distance and velocity ranges are systematically searched for the best solution assuming that the source time function has a total duration of approximately $15 \mathrm{sec}$ based on inspection of the waveforms. A series of overlapping triangular time functions with a $1 \mathrm{sec}$ rise time was used in modeling the source time function.

\section{Modeling Results}

The size and station distribution for this event limit the spatial resolution and resolvable detail using long-period data. Sipkin (1989) suggests that a time variable single-source model may fit the long-period data as well as the two source model proposed by Bent et al. (1989). However, the various single-point and single-line source models investigated here were unable to explain the data. A two source model 


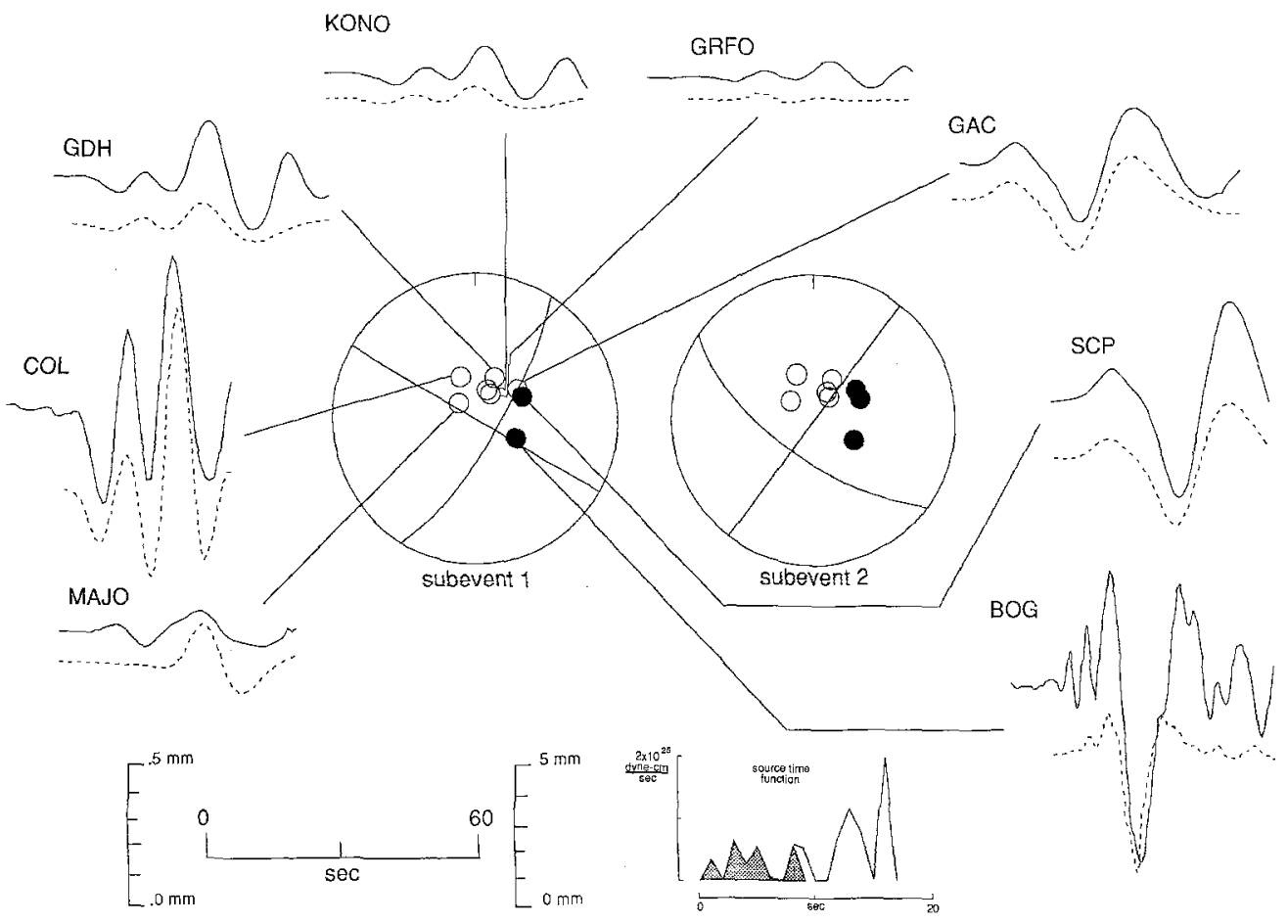

FIG. 3. Model 1. Observed (solid lines) and synthetic (dashed lines) long-period $P$-wave seismograms. Shown in the center of the figure is the lower hemisphere focal mechanism for the two subevents. Solid circles represent compressional and open circles dilatational first motions. Focal parameters are given in Table 1. The combined source time function for subevent 1 (shaded) and subevent 2 (unshaded) is shown at bottom right. Time and amplitude scales are shown at bottom left. Separate amplitudes scales are given for analog (left) and digital (right) instruments. Amplitudes of the observed and synthetic seismograms are normalized to the identical instrument at a distance of $40^{\circ}$ with a peak magnification of 1500 .

provides a much better fit. For subevent 1, centroid locations along the Elmore Ranch fault were tested. Data misfits increase as subevent 1 is moved further away from the epicenter. However, a point source closer than $10 \mathrm{~km}$ to the epicenter is unresolvable from a point source at the epicenter. Either moment release along the Elmore Ranch fault during subevent 1 was not a substantial portion of the longperiod moment release or it occurred within $10 \mathrm{~km}$ to the epicenter of the event. In our final models, subevent 1 is a point source located at the epicenter. Since the epicenter lies near the intersection of the Elmore Ranch and Superstition Hills fault, the choice of fault plane is ambiguous. For the sake of discussion, we choose the northwest-southeast trending fault plane.

Investigation of various double source models suggests two possible source parameterizations. Model 1 consists of two temporally and spatially separate point sources. Spatial separation of the two sources is investigated by placing subevent 2 at $5 \mathrm{~km}$ intervals southeast of subevent 1 along the strike of the fault, $305^{\circ}$. Model 2 consists of one point source and one time-delayed propagating line source. Rupture velocity was modeled at $0.5 \mathrm{~km} / \mathrm{sec}$ intervals. In model 2 , the line source remains 


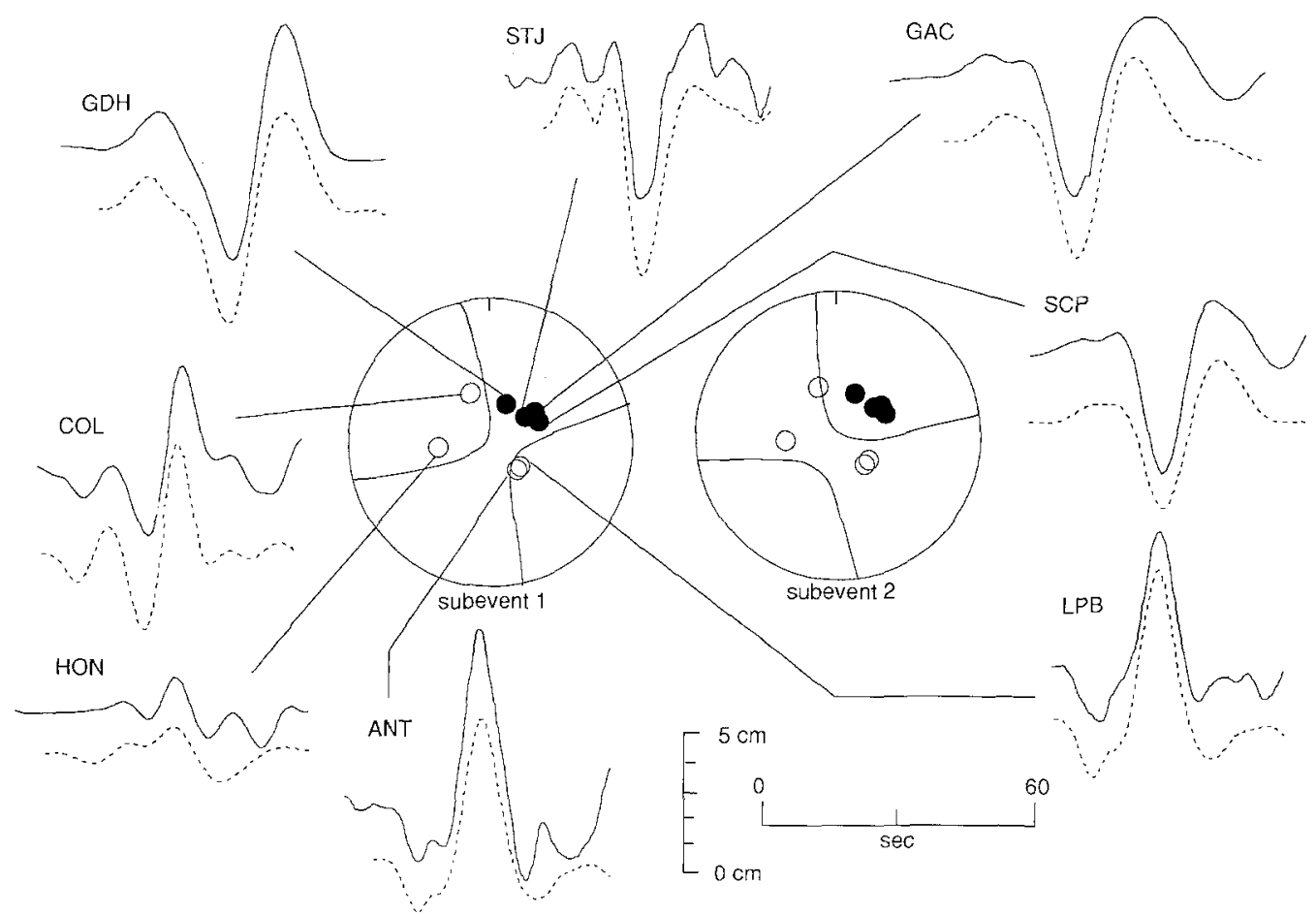

FIG. 4. Model 1. Observed (solid lines) and synthetic (dashed lines) long-period SH-wave seismograms. Amplitude scales are the same for analog and digital instruments. See Figure 3.

within a specified focal plane as the plane changes its orientation during the inversion. The final solutions for these two source models both fit the waveforms adequately. Final solutions for both models are given in Table 1 and waveforms are illustrated in Figures 3 to 6.

A summary of data misfits with respect to centroid depth for both models is given in Figure 7. Errors shown for model 1 (Fig. $7 \mathrm{a}$ and b) are for a fixed source separation distance of $20 \mathrm{~km}$. Errors shown for model 2 (Fig. 7c and d) are for a rupture velocity of $2.5 \mathrm{~km} / \mathrm{sec}$ for subevent 2 . Along each curve in Figures $7 \mathrm{a}$ and $\mathrm{c}$, the centroid depth for subevent 2 is fixed and the depth for subevent 1 is allowed to vary. The depth of subevent 1 is plotted along the $x$-axis and the depth of subevent 2 is as labeled on each curve. The depth for both subevents is fixed at $2 \mathrm{~km}$ intervals over a range of 2 to $12 \mathrm{~km}$. Similarly, along each curve in Figures $7 \mathrm{~b}$ and $\mathrm{d}$, the centroid depth for subevent 1 is fixed, and the depth of subevent 2 is allowed to vary. Focal mechanism, source separation time, and the source time function are determined in the inversion.

The final solution is chosen to lie along the curve with the overall lowest error level for both subevents (Fig. 7, bold line). As shown in Figures 7 a and c, centroid depth for subevent 1 is not a robust feature. In Figures $7 \mathrm{~b}$ and $\mathrm{d}$, the solutions with the smallest errors for subevent 2 range from 4 to $8 \mathrm{~km}$ in depth. This is the preferred depth range for both subevents and for all source models considered. The 


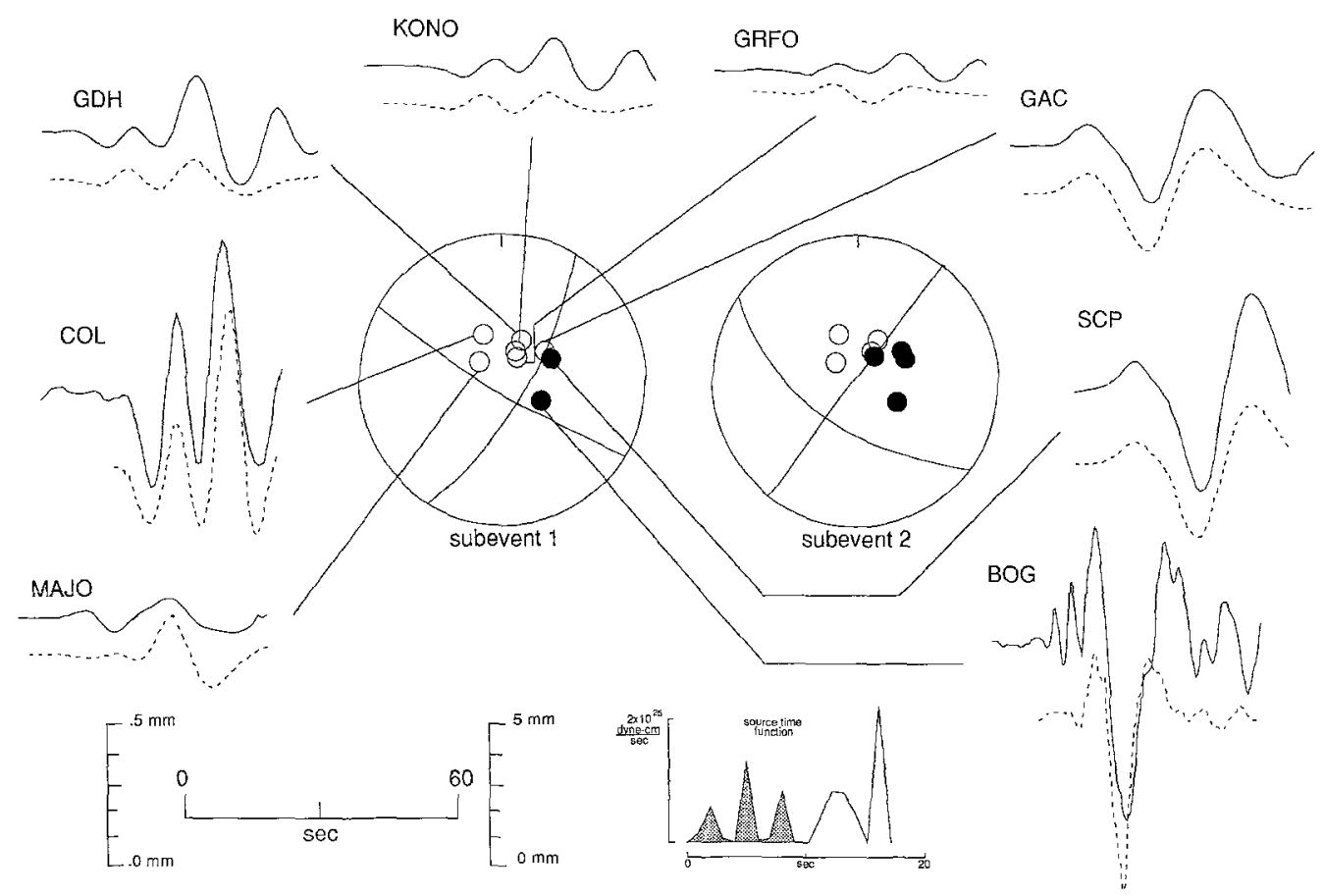

Frg. 5. Model 2. Observed (solid lines) and synthetic (dashed lines) long-period $P$-wave seismograms. See Figure 3.

best solution marked by a large dot in Figure 7 occurs when the centroid depth for subevent 1 and subevent 2 is 4 and $6 \mathrm{~km}$, respectively. This solution has the lowest error of all solutions tested.

In the inversion, formal errors for each solution are small. A more realistic estimation of the model errors are determined from the range of acceptable least error solutions. In model 1 , subevent 2 occurs at a distance of 15 to $20 \mathrm{~km}$ from subevent 1 . In model 2 , the rupture velocity may be as low as $1.5 \mathrm{~km} / \mathrm{sec}$. A velocity of $2.5 \mathrm{~km} / \mathrm{sec}$ is preferred since the overall level of data error is lower. This velocity is $0.7 V_{s h}$ of the shear-wave velocity in the layer. Within the above depth, distance and velocity ranges, the strike is well constrained to $\pm 1^{\circ}$ and the dip and rake are resolved to approximately $\pm 5^{\circ}$ for both models and subevents.

Overall waveform and amplitude match between both models and the data is good. Only HON ( $S$ wave) and MAJO ( $P$ wave) are not well matched. Unfortunately, these stations lie near nodes and provide the only data west of the Superstition Hills fault. Using a faster crustal structure more appropriate for the western side of the Superstition Hills fault has no significant effect on the waveforms or the focal mechanism solution. To further explore the range of solutions, we force a fit by overweighting HON and MAJO by 20 times the maximum weight in the inversion to obtain reasonable waveform matches to these two stations. The resulting model 


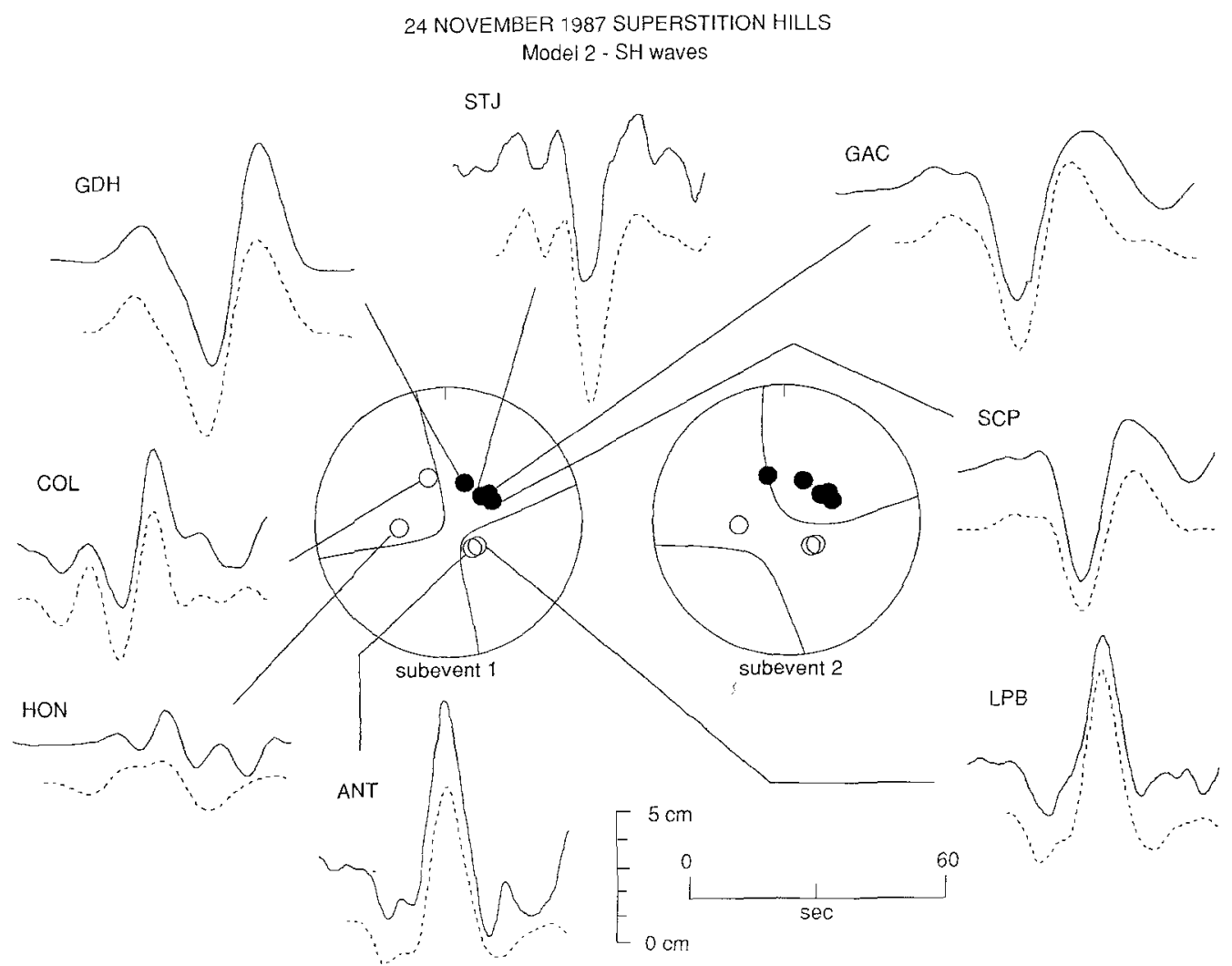

FIG. 6. Model 2. Observed (solid lines) and synthetic (dashed lines) long-period SH-wave seismograms. Amplitude scales are the same for analog and digital instruments. See Figure 3.

has two main differences from our final solutions. First is the difference in fault dip with subevent 1 now dipping to the east and subevent 2 near vertical. Hence, stations to the west appear to prefer dips near vertical while stations to the east prefer a westward dip of $70^{\circ}$. A conservative estimate would place the dip between 70 to $80^{\circ}$ to the west. This estimation is consistent with the magnitude and dip direction of the focal mechanism determined in the Harvard Centroid Moment Tensor (CMT) solution but opposite in direction to the model of Bent et al. (1989) (see Table 1).

The second difference is the change in the source time function. The net effect is to decrease the separation time between subevent 1 and the largest moment releasing episode in subevent 2. That is, to explain the waveforms at HON and MAJO, the relative travel time between the two subevents must be less than the travel time to the remainder of the stations. This suggests that the different source structure on the opposite sides of the Superstition Hills fault has some effect on the final solution. However, since both stations are located near nodes, the above results are not conclusive. Additional data to the west away from $P$-wave nodes are needed to illustrate more clearly any crustal effects.

For both models, the source time functions of each subevent have very little or no overlap and are very irregular. Irregularity can be attributed to the particular 
Model 1
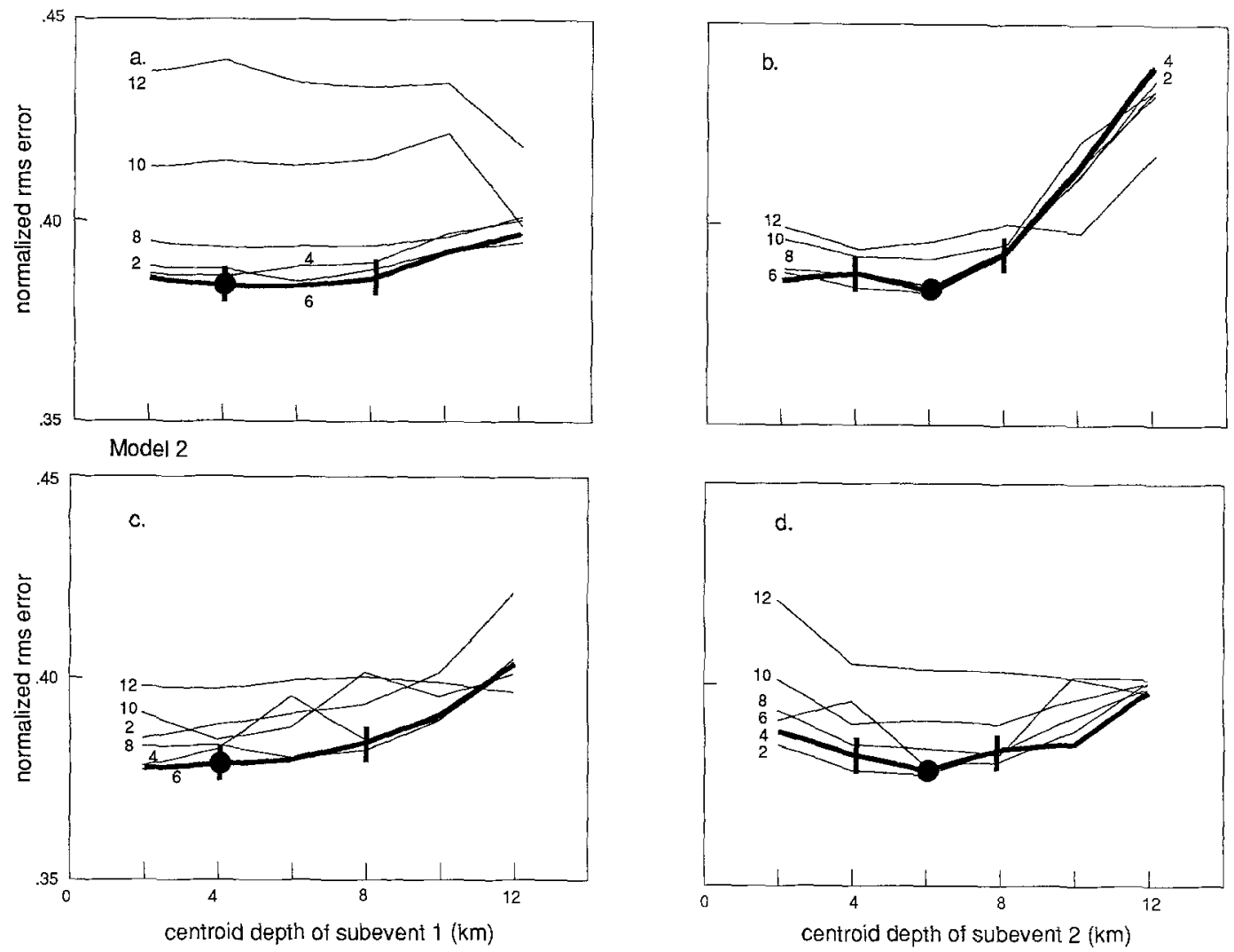

FIG. 7. Data misfits for model 1 and model 2. Plotted is the normalized rms error verses centroid depth for the two subevents. Errors for model 1 ( $7 \mathrm{a}$ and b) are for a source separation distance of $20 \mathrm{~km}$. Errors for model 2 ( $7 \mathrm{c}$ and d) are for a rupture velocity for subevent $2 \mathrm{of} 2.5 \mathrm{~km} / \mathrm{sec}$. For each curve in Figures $7 \mathrm{a}$ and $\mathrm{c}$, the depth of subevent 2 is held constant and the depth of subevent 1 is allowed to vary. The depth of subevent 1 is plotted along the $x$-axis and the depth of subevent 2 is as labeled on each curve. Depths for both subevents range from 2 to $12 \mathrm{~km}$. Similarly, for each curve in Figures $7 \mathrm{~b}$ and $\mathrm{d}$, the depth of subevent 1 is held constant and the depth of subevent 2 is varied. Drawn with a bold line is the curve that contains our preferred solution. In Figures $7 \mathrm{a}$ and $\mathrm{c}$, this curve is for a depth of $6 \mathrm{~km}$ for subevent 2 and in Figures $7 \mathrm{~b}$ and $\mathrm{d}$, for a depth of $4 \mathrm{~km}$ for subevent 1 . The large dot marks the depth of the preferred solution and the bars delineate the acceptable depth range.

parameterization used in the inversion which does nothing to insure the smoothness of the rupture process. Source elements with a longer time duration can be used to achieve an overall smoother source time function with some deterioration of waveform match. The total moment for both models is less than but in good agreement with that of Bent et al. (1989) and Sipkin (1989) and comparable to the the Harvard CMT solution (Table 1). Total moment corresponds to a $M_{w}=6.5$.

\section{Discussion}

Figure 8 summarizes the fault rupture models in this and previous studies along with aftershock, afterslip, and structural data. Symbols as noted in the figure represent point sources for different models. Line sources are represented by bold arrows. 


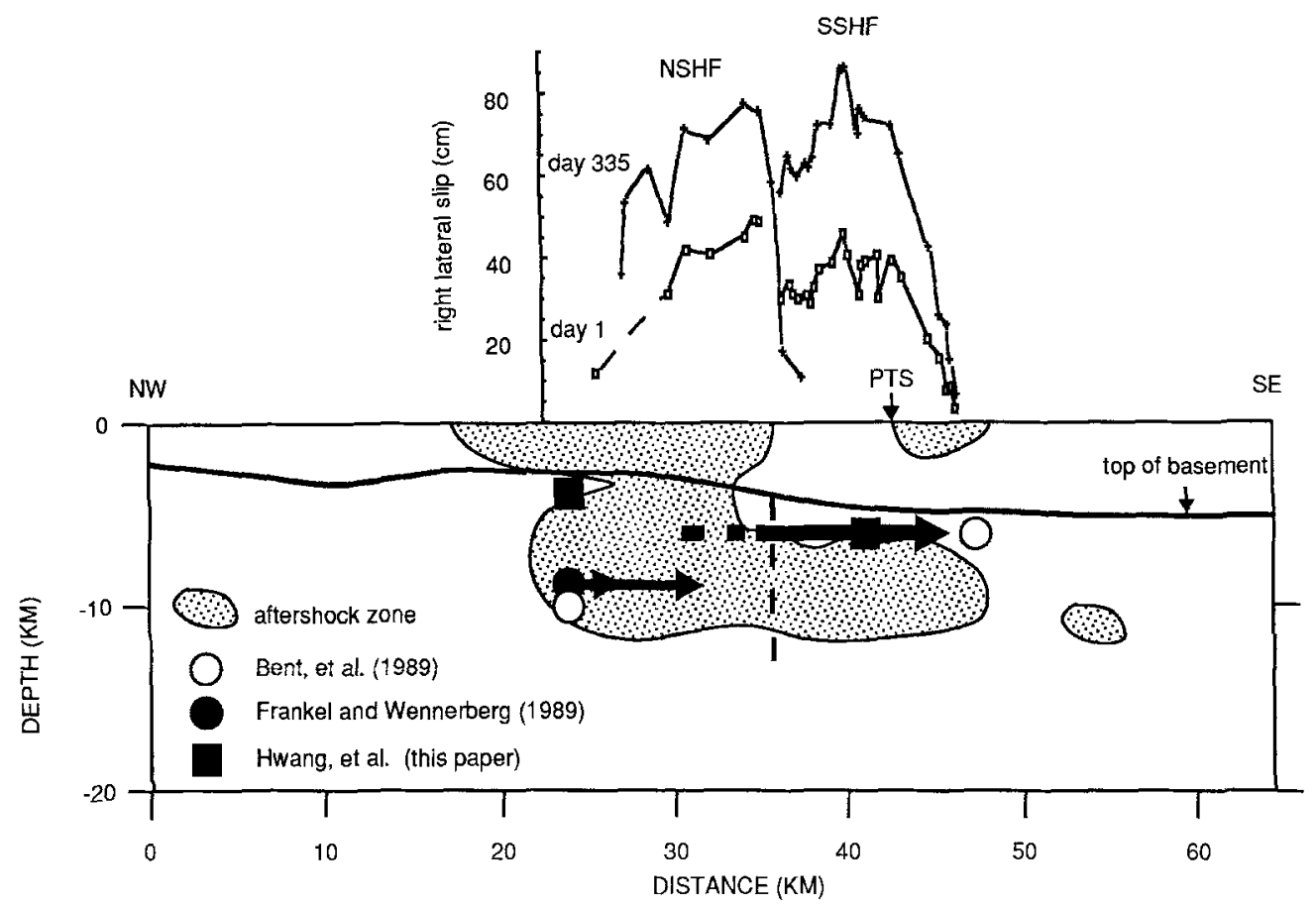

FIG. 8. Northwest-southeast cross section parallel to the Superstition Hills fault summarizing fault rupture models and slip history along the fault. The top figure shows afterslip plotted along the fault for 1 day and 335 days after the earthquake (after Williams and Magistrale, 1989). The bottom figure outlines the aftershock area (thin line, see Fig. 2) and basement topography (bold line, after Kohler and Fuis, 1986). The bold dashed line separates crystalline basement to the north (left) from metasedimentary basement to the south (right). Symbols as noted in the figure show source location and lateral extent for rupture models from this and previous studies. Abbreviations: PTS, Parachute Test Site; others are as noted in Figure 1. See Table 1 for source parameters.

In this study, both models 1 and 2 give a reasonable fit to the data. Both solutions indicate a steep, westerly dipping fault plane for subevent 1 and a $70^{\circ}$ westerly dipping fault plane for subevent 2 . The western dip agrees broadly with the location of the aftershocks to the west of the surface trace of the fault (Fig. 1). In both models, the centroid for subevent 1 lies at or near the epicenter. Subevent 1 nucleates at a depth of $2 \mathrm{~km}$ but has a centroid depth of $4 \mathrm{~km}$. Most of the moment release for subevent 2 lies along the southern segment of the Superstition Hills fault at a depth of $6 \mathrm{~km}$. For subevent 2, model 1 places a point source between 15 to $20 \mathrm{~km}$ southeast of subevent 1 along the strike of the fault. Model 2 distributes the source along a line at a distance of 10 to $22 \mathrm{~km}$ southeast from subevent 1 . Assuming a lower rupture velocity of $1.5 \mathrm{~km} / \mathrm{sec}$ would move this to a distance of 6 to $14 \mathrm{~km}$. This lower distance bound is illustrated by a bold dashed line in Figure 8 . The upper distance bound, $22 \mathrm{~km}$, agrees with the extent of surface rupture along the Superstition Hills fault (Sharp et al., 1989). Moment release along the southern segment accounts for two thirds of the total moment release for this earthquake. No significant moment release is seen along the Wienert fault.

The timing of the two subevents proposed by Bent et al. (1989) correlates with the timing of the two subevents in model 1 and model 2, but their locations differ substantially. Bent et al. (1989) place their second subevent due south of their first 
subevent at a preferred separation distance of $30 \pm 10 \mathrm{~km}$. Constraining the first subevent to lie along the Elmore Ranch fault and the second subevent to lie along the Superstition Hills fault would place their first subevent between 16 and $33 \mathrm{~km}$ northeast of the epicenter and their second subevent between 11 and $31 \mathrm{~km}$ southeast of the epicenter. A distance greater than $10 \mathrm{~km}$ northeast from the epicenter for the first subevent is not supported by this study. The lack of afterslip and aftershocks also do not support a large moment releasing subevent along the Elmore Ranch fault for the first subevent (Frankel and Wennerberg, 1989). Placing Bent et al.'s (1989) first subevent on the Superstition Hills fault would make a correlation of the second subevent with the surface trace of the Superstition Hills fault difficult.

The model of Frankel and Wennerberg (1989) show some similarities to models 1 and 2 . Subevent 1 correlates with their subevent 1 and 2 , where their subevent 1 represents the nucleation point of the earthquake. The timing of their subevent 3 correlates with subevent 2 , but the position of the sources differ. Slip for their subevent 3 starts at $0 \mathrm{~km}$ and does not extend past $8 \mathrm{~km}$ (see Fig. 8) even though surface rupture went well beyond this point. Also, total moment for their model is one sixth of what is observed at long periods (see Table 1). Hence, their model may not account for all of the slip along the fault.

Model 1 and model 2 are still consistent with the raw strong-motion data. The record from PTS located $18 \mathrm{~km}$ from the epicenter on the Superstition Hills fault suggests that significant moment release did not go beyond that station (Frankel and Wennerberg, 1989). Even though surface rupture continued along the trace of the fault out to $24 \mathrm{~km}$, the magnitude of surface slip dies off rapidly beyond PTS (Fig. 8). This distance falls within the range of our estimate of the position and extent of subevent 2 in both models. If the maximum extent for subevent 2 is 18 $\mathrm{km}$, this would imply a slightly slower rupture velocity in model 2 of $2.25 \mathrm{~km} / \mathrm{sec}$. The strong-motion data also indicate directivity towards the northeast along the Elmore Ranch fault (Frankel and Wennerberg, 1989; Wald and Somerville, 1988). Any moment release within $10 \mathrm{~km}$ of the epicenter along the Elmore Ranch fault is not resolvable from the long-period data.

Figure 8 compares the depth of moment release determined here, 4 to $8 \mathrm{~km}$, to the depth distribution of the aftershocks. The aftershocks lie mostly between 1 to $11 \mathrm{~km}$ depth. Along the northern segment of the fault, relatively few aftershocks lie between 2.5 to $5 \mathrm{~km}$ depth and in the south, between 2 to $8 \mathrm{~km}$. This is in agreement with studies of slip distribution along faults that find fewest aftershocks in areas of greatest slip (Doser and Kanamori, 1986; Mendoza and Hartzell, 1988) and greatest moment release (Schwartz et al., 1989) on the fault plane. Here we assume regions of greatest moment release correspond to areas of high slip. The centroid depth of both subevents in this study is generally shallower than the depths determined in the previous studies.

The model of Frankel and Wennerberg (1989) suggests that high frequency energy radiated predominately from the northern end of the fault. Combined with the results from models 1 and 2, this suggests that both high-frequency and lowfrequency energy radiated in the epicentral region along the northern segment of the Superstition Hills fault, while only low frequency energy radiated from the southern segment. This agrees with previous studies that indicate a different behavior for the two fault segments. In models 1 and 2, the northern segment dips near vertically and the southern segment dips steeply towards the west. The northern segment had a smaller proportion of afterslip than the southern segment 
(Williams and Magistrale, 1989), and more aftershocks (Magistrale et al., 1989). The boundary between the northern and southern segments lies at a step in the basement. This step separates the deeper sediments (4 to $5 \mathrm{~km}$ thick) of the southern segment which overlie metasedimentary basement from the thinner sediments $(2 \mathrm{~km}$ thick) of the northern segment which overlie crystalline basement (Fig. 8).

\section{Conclusions}

We inverted teleseismic body waves of the 24 November 1987, Superstition Hills earthquake using the method of Nabelek (1984, 1985). We obtained two multiple source models. In both models, subevent 2 begins $8 \mathrm{sec}$ after the initiation of subevent 1 and has two thirds of the total moment. The total moment for both models is approximately $8 \times 10^{25}$ dyne-cm. In model 1 , the first point source occurs under the epicenter, followed by a second point source 15 to $20 \mathrm{~km}$ away southeast along strike of the fault. In model 2 , the first point source is followed by a line source of $8 \mathrm{sec}$ duration rupturing southeast at 1.5 to $2.5 \mathrm{~km} / \mathrm{sec}$. Sources for both models are between 4 to $8 \mathrm{~km}$ depth. The fault dip changes from near vertical near its northern end to about $70^{\circ}$ near its southern end.

Moment release for subevent 1 occurs in the epicentral region and radiates both short- and long-period energy. A small portion of the Elmore Ranch fault $(<10 \mathrm{~km})$ may have re-ruptured during subevent 1 or alternatively, all moment release for both subevents was confined to the Superstition Hills fault. The second subevent ruptured the southern segment of the Superstition Hills fault radiating a substantial portion of the long-period energy resolved in this study. The difference in rupture characteristics and fault dips seen teleseismically is also reflected in aftershock and afterslip data, and crustal structure underlying the two fault segments.

\section{ACKNOWLEDGMENTS}

We thank the personnel at the WWSSN, CAND and USGS for making the data available to us. A. Bent and D. Wald reviewed a previous version of this manuscript for us. T. Heaton solved our timing problem by suggesting the use of the Borrego Mountain earthquake. Numerous discussions with D. Helmberger and T. Heaton were helpful. This work was supported by an NSF Graduate Fellowship, NSF Grant EAR-86-18189 and the USGS under contract 14-08-001-G1356 and 14-08-001-G1354. Contribution No. 4773, Division of Geological and Planetary Sciences, California Institute of Technology, Pasadena, California.

\section{REFERENCES}

Bent, A. L., D. V. Helmberger, R. J. Stead, and P. Ho-Liu (1989). Waveform modeling of the November 1987 Superstition Hills earthquake, Bull. Seism. Soc. Am. 79, 500-514.

Doser, D. I. and H. Kanamori (1986). Depth of seismicity in the Imperial Valley region (1977-1983) and its relationship to heat flow, crustal structure, and the October 15, 1979, earthquake, J. Geophys. Res. 91, 675-688.

Frankel, A. and L. Wennerberg (1989). Rupture process of the $M_{S} 6.6$ Superstition Hills earthquake determined from strong-motion recordings: application of tomographic source inversion, Bull. Seism. Soc. Am. 79, 515-541.

Fuis, G. S., W. D. Mooney, J. H. Healy, G. A. McMechan, and W. J. Lutter (1982). Crustal structure of the Imperial Valley Region, in The Imperial Valley, California, earthquake of October 15, 1979, U.S. Geol. Surv. Profess. Pap. 1254, 25-50.

Hanks, T. C. and C. R. Allen (1989). The Elmore Ranch and Superstition Hills earthquakes of 24 November 1987: introduction to the special issue, Bull. Seism. Soc. Am. 79, 231-238.

Herrin, E. (1968), Introduction to "1968 Seismological Tables for P Phases," Bull. Seism. Soc. Am. 58, $1193-1241$.

Kohler, W. M. and G. S. Fuis (1986). Travel-time, time-term, and basement depth maps for the Imperial Valley Region, California, from explosions, Bull. Seism. Soc. Am. 76, 1289-1303. 
Langston, C. A. and D. V. Helmberger (1975). A procedure for modelling shallow dislocation sources, Geophys. J. R. Astr. Soc. 42, 117-1390.

Magistrale, H., L. Jones, and H. Kanamori (1989). The Superstition Hills, California, earthquakes of 24 November, 1987, Bull. Seism. Soc. Am. 79, 239-251.

Mendoza, C. and S. H. Hartzell (1988). Aftershock patterns and main shock faulting, Bull. Seism. Soc. Am. 78, 1438-1449.

Nabelek, J. (1984). Determination of earthquake source parameters from inversion of body waves, Ph.D. Dissertation, Massachusetts Institute of Technology, Boston, Massachusetts, $360 \mathrm{pp}$.

Nabelek, J. (1985). Geometry and mechanism of faulting of the $1980 \mathrm{El}$ Asnam, Algeria, earthquake from inversion of teleseismic body waves and comparison with field observations, J. Geophys. Res. 90, 12713-12728.

Schwartz, S. Y., J. W. Dewey, and T. Lay (1989). Influence of fault plane heterogeneity on the seismic behavior in the Southern Kurile Islands Arc, J. Geophys. Res. 94, 5637-5649.

Sharp, R. V., K. E. Budding, J. Boatwright, M. J. Ader, M. G. Bonilla, M. M. Clark, T. E. Fumal, K. K. Harms, J. J. Lienkaemper, D. M. Morton, B. J. O'Neill, C. L. Ostergren, D. J. Ponti, M. J. Rymer, J. L. Saxton, and J. D. Sims (1989). Surface faulting along the Superstition Hills fault zone and nearby faults associated with the earthquakes of 24 November 1987, Bull. Seism. Soc. Am. 79, 252281.

Sipkin, S. A. (1989). Moment-tensor solutions for the 24 November 1987 Superstition Hills, California earthquake, Bull. Seism. Soc, Am. 79, 493-499.

Wald, D. J. and P. G. Somerville (1988). Simulation of accelerograms of the 1987 Superstition Hills earthquake sequence, Paper presented at SSA Meeting, Honolulu, Hawaii, 24-27 May 1988.

Williams, P. L. and H. W. Magistrale (1989). Slip along the Superstition Hills fault associated with the 24 November 1987 Superstition Hills, California, earthquake, Bull. Seism. Soc. Am. 79, 390-410.

\section{SEISMOLOGiCAL LaBoratory \\ California Institute of TeChNOLOGY \\ Pasadena, CALifornia 91125}

Manuscript received 21 July 1989 